\title{
13. Universities as internship regulators: Evidence from Australia ${ }^{1}$
}

\section{Anne Hewitt}

\subsection{INTRODUCTION}

Many universities offer students the opportunity to undertake an internship in a workplace outside the university (or one operated jointly with an external partner) as a part of their course of study. It is often assumed that the involvement of universities ensures these opportunities are better regulated and of higher quality than other internships. For example, the 2014 Council of the European Union recommendation on a quality framework for traineeships ${ }^{2}$ explicitly excludes educational internships on the basis that they are 'of better quality, due to the quality assurance by the educational institutions ... involved' ${ }^{3}$ This chapter explores that assumption by considering the educationally focused regulation of internships in three jurisdictions (Australia, England and France) and critically examining the regulatory role played by Australian universities.

In Australian educational regulation, educational internships are referred to as work-integrated learning (WIL). ${ }^{4}$ This chapter adopts that term. Section 13.2 introduces some key issues associated with WIL. Section 13.3 explores the Australian regulation of WIL, while section 13.4 investigates the regula-

1 The research that informs this chapter was conducted with the support of the Australian Research Council's Discovery Projects funding scheme ('Regulating Post-Secondary Work Experience: Labour Law at the Boundary of Work and Education', DP150104516). The enormous contribution to that project of my fellow Chief Investigators, Professor Emerita Rosemary Owens, Professor Andrew Stewart and Associate Professor Dr Joanna Howe, is gratefully acknowledged.

2 Council Recommendation of 10 March 2014 on a Quality Framework for Traineeships [2014] OJ C88/1.

3 European Commission, 'Applying the Quality Framework for Traineeships' (2016) European Commission Staff Working Document 324, 4.

4 This definition of WIL is drawn from Tertiary Education Quality and Standards Agency, Guidance Note: Work-Integrated Leaning (TEQSA 2017) 1. 
tory role being played by Australian universities using data from a national study of the regulation of internships. Section 13.5 outlines the regulatory regimes which apply to WIL in England and France, and considers whether any of the issues identified from the Australian data may be relevant to these jurisdictions. Section 13.6 concludes with a number of insights into the utility of educational regulation.

The absence of empirical or other evidence about the 'impact or effectiveness' of regulatory regimes governing internships has caused a substantial gap in our understanding to date. ${ }^{5}$ This chapter begins to fill this gap by considering whether laws in one jurisdiction that seek to ensure the quality of educational internships are having their intended effect, and whether those insights may be relevant elsewhere. A comprehensive evaluation of the role of universities as regulators is beyond the scope of this chapter. Instead, it focuses on their role in relation to regulation directed towards ensuring educational quality. This focus has been chosen because it is arguably core business for universities, and because concentrating on the educational aspects of internships complements the other foci in this collection.

The three jurisdictions that will be considered demonstrate two very different regulatory approaches but are unified by the regulation in each being predominantly recent, with much of it enacted in the past decade. England is considered because its regulatory regime is similar to that in Australia, with both having a dedicated educational regulator applying relatively broad-brush pedagogically focused regulations. In contrast, France takes a very different approach, with much more stringent regulation of WIL and dual enforcement of regulation from both universities and workplace regulators.

\subsection{INTRODUCING WIL}

Work-integrated learning is a growing phenomenon. Universities Australia undertook a national survey of the WIL activities that occurred in 2017 across Australia's 39 comprehensive universities. ${ }^{6}$ That survey found that more than one-third of enrolled tertiary students (451 263 students) had one or more WIL experience in 2017, and 555403 of these activities were undertaken. ${ }^{7}$ A 2013 survey of people aged 18-35 years in 27 European Union countries found that

5 Andrew Stewart, Rosemary Owens, Anne Hewitt and Irene Nikoloudakis, 'The Regulation of Internships: A Comparative Study' (2018) ILO Employment Policy Department Working Paper No 240, xiii, 25.

6 Universities Australia, Work-Integrated Learning in Universities: Final Report (Universities Australia 2019).

7 Ibid 8. 
46 per cent had undertaken at least one paid or unpaid traineeship, ${ }^{8}$ though the figure was well over 70 per cent in some countries. For survey respondents who had completed internships, the majority did so while they were studying. ${ }^{9}$ Although the survey did not require participants to indicate whether their internship experience was a part of their course of study, it is safe to assume that a significant number were. For example, it could be assumed that the great majority of internships undertaken in France were undertaken as a part of a course of study, because since 2011 the only internships that are legal in that country are those completed as part of a course of study.

While stakeholders and students have embraced WIL around the world, it is associated with a variety of risks. These include what could be described as workplace risks, such as students being subject to discrimination, bullying or harassment in the workplace, being injured, or exploited by being required to work long hours or undertake work without proper safety measures in place. In addition, there are also educational risks, including that a poorly planned, supervised or assessed WIL opportunity can deliver less than optimal learning opportunities. $^{10}$

Occupying dual roles as both student and worker exposes participants in WIL to multiple vulnerabilities. Students often need to successfully complete a WIL placement in order to graduate from their degree, be eligible for admission into a profession with a work experience prerequisite, and to secure work experience, references and contacts to assist them to gain graduate employment. These factors make it difficult for student participants to complain about poor treatment, exploitation or inadequate learning outcomes. This is particularly true as, in many circumstances, the only remedy available when a WIL opportunity is deemed unsatisfactory is to withdraw the student and place them elsewhere. This often involves disruption and cost for the student, and can delay their graduation and professional admission.

Different jurisdictions take radically different approaches to regulating WIL, including the extent to which, and how, they seek to manage its educational quality. These regulatory regimes are of interest not only to regulatory schol-

8 'Traineeships' were defined as 'a limited period of work experience and training spent in a business, public body or non-profit institution by students or young graduates. This excludes regular jobs': TNS Political \& Social, The Experience of Traineeships in the EU (Flash Eurobarometer 378, Directorate-General for Employment, Social Affairs and Inclusion, European Commission 2013) Q1.

9 Ibid 15.

10 Some of the workplace and educational benefits and risks of WIL are discussed in Anne Hewitt, 'Avoiding the Trap of Exploitative Work: A National Approach to Making Work-Integrated Learning Effective, Equitable and Safe' (2018) 31 Aust J Lab L 101. 
ars, but also to academics and others concerned to ensure WIL delivers quality learning outcomes. There is extensive pedagogical literature considering how to design and run WIL to maximize students' learning. A full analysis of that literature is not necessary here, save to note that regulation directed to educational quality establishes minimum standards for WIL within the jurisdiction. This has the potential to ensure that participation in WIL is a valuable learning experience, not mere exploitation. However, there are strong arguments that, in most jurisdictions, the regulation establishes minimum thresholds and that not every example of compliant WIL will be of high quality. Nonetheless, these education-focused regulations are significant as they set a threshold applicable across the education sector.

It is also interesting to consider the content and impact of the educational regulation of WIL since, as discussed previously, it is often assumed work experience associated with education is of higher quality than other internships. The Council of the European Union made this assumption in its 2014 recommendation, as discussed in the introduction to this chapter. Whether this is really the case can only be determined by critically evaluating the relevant regulatory regimes and their implementation.

\subsection{THE REGULATION OF TERTIARY WIL IN AUSTRALIA}

In 2012 Perlin suggested that students were potentially being charged tuition for completing internship courses which did not require the provider to incur expenses for facilities or instruction. ${ }^{11}$ In Australia this risk is controlled by the Higher Education Support Act 2003 (Cth), which provides that, if WIL is to receive government funding at the same level as other university courses, it needs to be directed and meet specific academic criteria to do with the quality and nature of the university input. ${ }^{12}$

Australian universities are regulated by the Tertiary Education Quality and Standards Agency (TEQSA), an independent statutory authority, established by the Tertiary Education Quality and Standards Agency Act 2011 (Cth) (the TEQSA Act). The TEQSA Act requires all Australian universities to

\footnotetext{
11 Ross Perlin, Intern Nation: How to Earn Nothing and Learn Little in the Brave New Economy (rev edn, Verso 2012) ch 8.

12 See ss 33-30(1) regarding non-payment for 'work experience in industry' and the definition of that term in ch 1, cl 1(1). See also Higher Education Support Act Administration Guidelines 2012, 5.5.1, which provide that, if the educational provider meets criteria that include monitoring students, providing direction of their work, and managing the educational content and objectives of placements and assessing student learning, then a placement is not regarded as 'work experience in industry'.
} 
be registered..$^{13}$ Each course of study offered by a registered university must comply with the Provider Course Accreditation and Qualification Standards. ${ }^{14}$ Self-accrediting institutions (all 40 Australian universities are self-accrediting) can develop a course of study and begin delivering it without any formal advance evaluation by TEQSA, ${ }^{15}$ but remain responsible for ensuring it complies with the standards. TEQSA is authorized to conduct audits to evaluate compliance. ${ }^{16}$ If an audit reveals that a university has failed to comply with the standards, TEQSA can impose sanctions by shortening or cancelling the period of registration. ${ }^{17}$

The standards provide that WIL arrangements must be 'quality assured, including assurance of the quality of supervision of student experiences'. ${ }^{18}$ In addition, a TEQSA Guidance Note on Work-Integrated Learning makes it clear that, while the standards do not prescribe any particular type of WIL compliance, they require every WIL experience to be 'well-conceived, educationally sound and its implementation ... quality assured and monitored by the provider' ${ }^{19}$ It is notable that these provisions do not provide much detail about what constitutes high-quality WIL, and could logically be applied to any learning experience.

The Education Services for Overseas Students Act 2000 (Cth) (ESOS Act) sets out a legal framework governing the delivery of education to international students in Australia on a student visa. It provides that a university that wishes to offer courses to overseas students must be registered, ${ }^{20}$ must disclose specific information about WIL to overseas students, ${ }^{21}$ and comply with the National Code of Practice for Providers of Education and Training to Overseas Students 2018 (Cth) (the National Code). Standard 11 of the National Code requires TEQSA ${ }^{22}$ approval for various modes of study including work-based

\footnotetext{
TEQSA Act, $\mathrm{s} 4$.

Higher Education Standards Framework (Threshold Standards) 2015.

15 TEQSA Act, s 45.

16 Ibid s 59.

17 Ibid ss 99-101.

18 Higher Education Standards Framework (Threshold Standards) 2015, standard

19 TEQSA (n 4) 2.

20 ESOS Act, pt 2. A list of registered providers can be found at Department of Education, Skills and Employment, 'Commonwealth Register of Institutions and Courses for Overseas Students', http://cricos.education.gov.au/, accessed 30 March

21 See eg Code of Practice for Providers of Education and Training to Overseas Students 2018 (Cth), standards 1.2.2, 2.1.2, 3.3.1.

22 ESOS Act, $\mathrm{s} 6 \mathrm{C}$ provides that the ESOS Agency for a registered higher education provider is TEQSA.
} 5.4.1. 2021. 
training. ${ }^{23}$ The Tertiary Education Quality and Standards Agency can also request the university demonstrate that 'any work-based training to be undertaken as part of the course is necessary for the student to gain the qualification and there are appropriate arrangements for the supervision and assessment of students', ${ }^{24}$ and that 'the provider and any partner they engage to deliver a course ... has adequate staff and education resources, including facilities, equipment, learning and library resources and premises' to properly deliver the course. ${ }^{25}$ Universities which do not comply with the ESOS Act or National Code can face sanctions including suspension or cancellation of registration, or imposition of conditions on registration. ${ }^{26}$

Despite the existence of a regulator with investigation and sanction powers, intra-university policies and practices remain critical to ensure that WIL offered by Australian universities is of a high quality. There are several reasons for this. An important reason is that TEQSA compliance audits are irregular, occurring in a seven-year cycle. ${ }^{27}$ In addition, TEQSA employs a risk-based audit procedure which means it can consider evidence of compliance on selected issues, which may or may not include WIL. ${ }^{28}$ A notable consequence of this principally self-regulating approach is that it is critical to evaluate intra-university compliance processes to determine the effectiveness of the regulation.

\subsection{AUSTRALIAN UNIVERSITIES' PERFORMANCE AS REGULATORS}

If the regulatory standards introduced above are to have any impact on the quality of WIL, it is necessary to consider not only regulatory content but also its implementation. The regulations target Australian universities, which are expected to implement the regulations in developing and delivering WIL. As a consequence, universities' response to the regulation is critical to regulatory compliance. ${ }^{29}$ The extent to which, and how, universities respond is explored here through an Australian case study, as at this stage no equivalent data from other jurisdictions exist.

\footnotetext{
Standard 11.1.2.

Standard 11.2.3.

Standard 11.2.5.

ESOS Act, s 83.

This is the registration period provided for in the TEQSA Act.

TEQSA Act, s 15.

9 Christine Parker and Vebeke Lehmann Nielsen, Explaining Compliance: Business Responses to Regulation (Edward Elgar 2011).
} 


\subsubsection{Research Methodology}

The empirical evidence informing this analysis is qualitative 'languaged data' comprising interview responses from 68 semi-structured interviews completed from May 2017 to January 2018. ${ }^{30}$ Those interviews were conducted at 15 diverse Australian universities located in five different Australian states, ${ }^{31}$ including universities with multi-state campuses, those located in the outer suburbs of a city, rural/regional universities and providers of distance education. $^{32}$

Interviews of 45-60 minutes were conducted with personnel involved with WIL in a variety of roles using an interview instrument with only minor differences for each of the cohorts. The interviews were digitally recorded, professionally transcribed and de-identified prior to analysis.

Analysis of the interview data occurred simultaneously with the data collection phase, which is common in a grounded theory approach. The qualitative data analysis software NVivo was used to code the interview transcripts manually against themes that were emerging from the material. In addition, NVivo facilitated keyword searches within the interview transcripts. For this chapter, the interview content which was identified by thematic code or keyword as being relevant to the regulation of educational quality of WIL was collated and considered to develop insights into the regulatory role of universities.

\subsubsection{Analysis}

An important preliminary point is how little direct reference to formal educational regulation was made in the interviews. The term 'TEQSA' was only used in 29 out of 68 interviews, despite being included in the interview instrument. The term 'ESOS' was not included in the interview instrument for any of the participant cohorts, but was raised in five interviews, exclusively by participants. The Higher Education Support Act 2003 (Cth) was obliquely referenced in two interviews, on both occasions by interviewees.

Analysis of the interview data suggested that the scarcity of explicit reference to the formal regulatory framework of tertiary WIL experiences reflected

30 Ethics Approval H-2016-254. See Donald E Polkinghorne, 'Language and Meaning: Data Collection in Qualitative Research' (2005) 52 J Counseling Psych 137, 137.

31 New South Wales, Queensland, South Australia, Victoria, Western Australia. Excluded were Tasmania and all Australian territories. Our rationale for the exclusions was time, cost and particularity (accounts in excluded regions would be sui generis).

32 These categories overlapped in some institutions; for example, a university could be both regional and have campuses in outer suburbs of cities in that region. 
a general lack of knowledge about the regulation. No participant informed us that they had received specific training regarding relevant educational regulation. On the contrary, most participants had an experience similar to the following:

I was sort of put in this position. They said, 'Well, this is your role. This is what you're going to do.' You know, you do get those online modules that you have to do about workplace health and safety, bullying, sexual harassment, all that sort of thing. You do those online. But I didn't get any formal training [on educational regulation], no ... And I don't know that the other staff members that are involved in programs would either.

Another interviewee explained it was assumed that the relevant people are aware of the regulatory framework: 'the assumption is that those staff for whom [educational regulation] is relevant understand it, they're aware of it and they recognize their responsibilities'.

One participant explained the lack of general knowledge of the education regulation on the basis that ensuring compliance with it was a specialist role within universities, and that 'ordinary' university employees were therefore not required to know about it: 'I think the attitude of a lot of universities appears to be: there are the team that get the ulcers dealing with those things, that they will tell you what [to do], and how you have to do it.'

It is true that if universities implement processes to ensure compliance with the regulatory regime, the individuals undertaking those processes might not be aware they were engaged in compliance. The interview data regarding each university's internal quality assurance processes were analysed to see whether there was any evidence to support this, and the results were mixed. In some universities it seemed that the institution had developed courses and approval processes which addressed the WIL regulatory requirements. For example:

[I]n our course design process, which I won't go into it in all in detail, but ... work-integrated learning is built into that. So for every single unit that you develop, you have to, I've got a whole framework that I have developed around thinking about your assessment and the authenticity of it. So they have to assign a descriptor that reflects the authenticity, as in the work-integrated learning inherent in that assessment. In other words, it can't just be an experience; students have to evidence in their assessment.

While these interviews did not explicitly acknowledge any link between the educational regulation and the policies and processes being described, it is certainly possible to see them as an internal process for ensuring compliance with the regulation. This could be described as a method for ensuring 'compliance by design' with the relevant regulatory framework. Only one interviewee made this overt, explaining that the education regulation which underpinned the 
policy and procedural framework was explicitly referred to in the associated staff training package.

However, in other universities it was clear the course design and approval processes were generic, and did not explicitly respond to the regulatory requirements regarding WIL: 'when you introduce a WIL experience there's no extra questionnaire, you're just going through the normal course approval process'.

In a third cohort of universities, policies and processes could be described as 'catching up' to the growth of WIL pedagogies. Interviewees from these institutions made it clear that their policies were being crafted in the wake of a rapid expansion of WIL experiences, rather than the WIL experiences being developed in accordance with a policy: '[W]e put together a workplace learning website in this faculty and we realized there was no policy to load up onto it, so we are now writing one.'

This spectrum of responses strongly suggests that, at the time the interviews were conducted, not all universities had a robust internal system to ensure that WIL complied with the thresholds established by the educational regulation. While a number of universities were in the process of policy development or review, which might address this, our analysis raised further questions about how successful this would be. A number of participants expressed what could be described as 'policy abstinence'. That is, a perception that 'we drown in policies', and as a consequence they were choosing not to engage with those relating to WIL: 'When I was the [coordinator of an internship programme], I have to confess that I remained as blissfully ignorant as possible of any rules and regulations that were going to make things harder.' In addition, some interview participants described situations that could be described as 'policy ignorance':

I've been in universities for 10 years and I've come across random academics that you might be in a meeting with and their students go out and do, I guess you would call it work experience, and I'm like, 'Oh great, so who signs off your paperwork?' and they're like, 'What paperwork?'

In a broad sense, many of the interviewees identified tensions between the central university and discipline areas as a significant stumbling block to institution-wide regulatory compliance: 'I see a bit of a push/pull - the discussion is always, "Well we should have a policy, we should have a procedure, we should get everyone involved" and then everyone sits down and it's, "My area is different because - ".' In addition, some participants expressed significant 
dissatisfaction with the development of universally applicable policies and procedures. For example:

So it looks like there might be a new policy coming, but the creation of that policy, the mechanics of how it was generated seem a little bit vague? ... [It was] [a]uthored by a whole bunch of people and they didn't talk to me or anyone else who does [WIL].

The disengagement from formal university policy typified in the previous quotations raises questions about the effectiveness of internal university processes to ensure regulatory compliance, regardless of the quality or content of the policy in question.

What does the previous analysis demonstrate about the role of universities as regulators? Before identifying key themes from the Australian data, it is worth noting that the analysis was restricted in a number of ways. First, it considered only how universities are acting as regulatory actors in relation to compliance with the regulation discussed in section 13.3. Secondly, the interview data considered are drawn from 68 interviews conducted at 15 universities. This is clearly not a comprehensive data set. However, it constitutes what the research team believed to be a reasonable sample to offer insights into the sector. A systematic literature review revealed that 'an overall norm of between approximately 15 and 60 participants ${ }^{33}$ is appropriate in organizational and workplace research. There was also a clear theoretical rationale behind the stratified purposive sampling strategy employed in selecting participants, which was intended to achieve breadth as well as depth in the resulting data. ${ }^{34}$

When the interview data regarding compliance with TEQSA, the ESOS Act and the Higher Education Support Act 2003 (Cth) are considered, three critical themes emerge. First, despite education being core business for Australian universities, the data suggest that many of those who work within universities are not well informed (or informed at all) about the regulatory framework governing it. Second, it does not appear that all universities are designing processes and policies which will ensure regulatory compliance. Instead, many of the processes and policies for course design and approval appear generic, and do not address the specific regulatory requirements for WIL. Third, while some universities had implemented processes to encourage regulatory compliance

33 Mark Saunders and Keith Townsend, 'Reporting and Justifying the Number of Interview Participants in Organization and Workplace Research' (2016) 27 Brit J Manage 836, 849.

34 Purposive sampling strategies are "non-random ways of ensuring that particular categories of cases within a sampling universe are represented in the final sample of a project': Oliver Robinson, 'Sampling in Interview-Based Qualitative Research: A Theoretical and Practical Guide' (2014) 11 Qual Res Psych 25, 32. 
by design, there were still issues of policy abstinence and policy ignorance which affected the utility of those processes in ensuring all WIL delivered by the institution was compliant with the regulation.

It is acknowledged that these themes are impressionistic in nature. This is the consequence of the research methodology and data analysis process used in the research project. However, to date this is the only extensive data set available which can provide insights into how universities are acting as regulators in the context of WIL.

The Australian regime described previously makes it clear that, despite having a national regulator (TEQSA), the regulation of WIL is predominantly occurring within universities themselves. The analysis suggests that internal university regulation of WIL, to the extent it is happening, is not framed by institutions themselves, nor those applying the internal processes, as a mechanism to ensure regulatory compliance. If compliance with the formal education regulation is not a central objective of the university processes, then the efficacy of those processes to ensure compliance must be in doubt. This is problematic, as the formal TEQSA enforcement processes are both irregular and non-comprehensive. In addition, the details of the outcomes of formal enforcement processes, such as TEQSA audits, are often not publicly available. This exaggerates the lamentable gap in regulatory compliance, which must lead us to critically evaluate the enforcement and effectiveness of the educational regulation considered here.

\subsection{REGULATING WIL IN FRANCE AND ENGLAND}

The regulatory approach in France and England is outlined for comparative purposes. ${ }^{35}$ Both jurisdictions have attempted to implement regulation that ensures WIL delivers learning outcomes for students, and is not merely exploitative work, but in very different ways.

\subsubsection{France}

In France the 2011 'Cherpion Law', which was amended in 2014, ${ }^{36}$ introduced a range of measures to regulate internships and protect interns from being

35 For an analysis of how 13 different countries approach the educational content of internships, see Stewart and others (n 5) 62-8.

36 Loi no 2011-893 pour le Développement de l'Alternance et de la Sécurisation des Parcours Professionnels (28 July 2011); loi no 2014-788 tendant au développement, à l'encadrement des stages et à l'amélioration du statut des stagiaires (10 July 2014). The French Ministry of Education has developed a standardized traineeship agreement, which contains all rights and obligations of the parties involved: Ministère de l'Édu- 
exploited. As a consequence of these reforms, open-market internships have effectively been outlawed, and the only legal internships are those undertaken under a tripartite agreement (convention de stage) between a student intern, host and educational institution. ${ }^{37}$ The convention de stage must specify the educational objectives of the internship and its conditions, including the activities the intern will undertake and the skills they will develop during the course of their internship. ${ }^{38}$ The legislation also requires that both the educational institution and host organization provide a supervisor for every intern, ${ }^{39}$ and strict limits have been imposed on the number of interns that supervisors can oversee ${ }^{40}$ In order to reduce the risk that an intern will be exploited, internships have been limited to a duration of six months, and for any arrangement exceeding two months the intern is entitled to compensation (although this is expressly stated not to be a salary). ${ }^{41} \mathrm{~A}$ range of other workplace protections are also extended to interns, including limits on daily and weekly working hours. ${ }^{42}$

The university teacher supervising an intern is responsible for ensuring compliance with the conditions of the convention de stage. ${ }^{43}$ Additional enforcement is undertaken by labour inspectors. Hosts are required to record interns on the staff register, ${ }^{44}$ which is intended to enable labour inspectors to identify fraudulent internships. If the labour inspectors find that a host organization has breached its obligations regarding the number of interns, tutors or the working hours of the intern, ${ }^{45}$ the organization may be fined. ${ }^{46}$ For other breaches the labour inspectors will inform the intern, their educational institution and staff of the host organization. ${ }^{47}$ In addition, host organizations must report the number of interns and their employment conditions in their annual

cation Nationale, de l'Énseignement et de la Recherche, Arrêté du 29 décembre 2014 relatif aux conventions de stage dans l'enseignement supérieur.

37 Code de l'éducation, art L 124-5. A doctoral student completing an internship requires a less comprehensive convention d'accueil, which does not contain extended details on the conditions of the internship, such as insurance or the stipend payment, and requires signature only by the researcher and the host institution.

38 Ibid arts D 124-4(4), L 124-2(2).

39 Ibid arts L 124-2(3), L 124-9.

40 Ibid arts R 124-13, D 124-3.

${ }_{41}$ Ibid art L 124-6. In 2020 compensation is $€ 591.49$ per month for a full-time internship.

$42 \quad$ Ibid art L 124-14.

43 Ibid art L 124-2(3) (created by loi no 2014-788, art 1).

44 Ibid art L 1221-13 (as amended by loi no 2014-788, art 3).

45 See ibid arts L 124-8 (number of interns), L 124-9 (host organization's obligation to designate a tutor), L 124-14 (intern's working hours).

46 Ibid art L 124-17 (created by loi no 2014-788, art 1).

47 Code du travail art L 8223-1-1 (created by loi no 2014-788, art 6). 
report. ${ }^{48}$ In theory this enables the work council to identify hosts that are in breach of the regulations.

This legislative approach is interesting because of its clear regulatory focus on genuine learning. This is indicated by the link with formal study, the prerequisite that learning outcomes and work are specified, and the supervision requirements. A focus on learning can also be implied from the time limit imposed on internships, and the requirements which ensure host organizations are not replacing paid workers with interns. ${ }^{49}$ However, in 2016 it was reported that some abuse of internships was still occurring in France; for example, 'employers not offering appropriate pay or using interns as cheap sources of labour rather than offering them structured training and work experience' ${ }^{50}$ This illustrates that, despite the quality of the regulation, consideration of enforcement is critical in order to determine whether the regulation is having the intended effect.

\subsubsection{England}

England has a very different regulatory framework, with an external regulator, the Office for Students (OfS), which was established by the Higher Education and Research Act 2017 (UK). The OfS maintains a register of English higher education providers, which are required to register if they, inter alia, wish to access public grant funding or student support funding. Conditions of registration include a number of criteria directed to provision of high-quality education, including delivery of well-designed courses, provision of support for all students to enable them to succeed, and delivery of successful outcomes for all students which are recognized and valued by employers and/or enable further study. ${ }^{51}$ The OfS is empowered to conduct reviews of institutions on the register to ensure compliance with those quality criteria, as well as the

48 Sarah Mongourdin-Denoix, 'Strengthened Regulation of Internships' (Eurofound, 12 December 2011), https://www.eurofound.europa.eu/publications/ article/2011/strengthened-regulation-of-internships, accessed 30 March 2021.

49 See Code de l'éducation, arts R 124-10 (created by decree no 2015-1359, art 1), L 124-8 (created by loi no 014-788, art 1), L 124-11 (created by loi no 2014-788, art $1(\mathrm{~V}))$.

50 Andrea Broughton, Martha Green, Catherine Rickard, Sam Swift, Werner Eichhorst, Verena Tobsch and others, Precarious Employment in Europe, Part 1: Patterns, Trends and Policy Strategy (University of Amsterdam 2016) 51, http://www .europarl.europa.eu/RegData/etudes/STUD/2016/587285/IPOL_STU(2016)587285 EN.pdf, accessed 30 March 2021.

51 Office for Students, Securing Student Success: Regulatory Framework for Higher Education in England (OfS 2018) Annex A 139-9. 
rest of the regulatory regime. ${ }^{52}$ However, the OfS has made it clear that it will not systematically conduct reviews on a scheduled cyclical basis. Instead, it will conduct reviews based on random sampling or if various risk indicators suggest there may be issues within an institution.

The OfS has adopted the Quality Assurance Agency (QAA) Quality Code for Higher Education (Quality Code) to provide guidance regarding compliance with the regulatory framework. The Quality Code sets out clear expectations for all UK higher education institutions. These are in 12 areas and include work-based learning. ${ }^{53}$ In each of these areas the Quality Code includes 'expectations' and 'core practices', compliance with which is mandatory in all parts of the UK, and 'common practices', which are not regulatory requirements in England. ${ }^{54}$ If an OfS review of an English university determines there is an issue with compliance with an expectation or core practice of the Quality Code, it has a number of potential responses. These include further investigations, enhanced future monitoring or imposing specific conditions on the university, and can extend to monetary penalties, suspension of registration and deregistration. ${ }^{55}$

The Quality Code contains some guidance relating to WIL; however, it is general in nature. Indeed, it is arguably relevant to almost any learning opportunity, rather than being particularly targeted towards WIL. A critical expectation is that 'courses are well-designed, provide a high-quality academic experience and enable a student's achievement to be reliably assessed'. ${ }^{56}$ Another expectation is that, '[w] here a provider works in partnership with other organisations, it has in place effective arrangements to ensure that the standards of its awards are credible and secure irrespective of where or how courses are delivered or who delivers them'. ${ }^{57}$

Since the OfS has been recently created, there is not yet enough information to evaluate whether its reviews will be effective in enforcing the standards for WIL. However, it is probable that some of the problems identified in relation to Australia will be relevant in this jurisdiction also.

\footnotetext{
52 Authorized under Higher Education and Research Act 2017 (UK), s 75. See Office for Students (n 51).

53 Quality Assurance Agency, UK Quality Code for Higher Education Advice and Guidance: Work-Based Learning (Quality Assurance Agency 2018).

54 Ibid 1.

55 Office for Students (n 51) 27.

56 Quality Assurance Agency (n 53) 3.

57 Ibid.
} 


\subsubsection{How do France and England 'Measure Up'?}

There are no data available to determine how English universities are performing as regulatory actors. However, there are many similarities in the regulatory regimes implemented there and operating in Australia. In particular, as in Australia, the risk-based approach proposed by the English OfS is likely to result in intra-university processes being important in the efficacy of the regulatory regime in ensuring WIL is a quality learning experience, not exploitation. While there are no data on which to rely, it is also plausible that the three themes identified which limit the effectiveness of university implementation of educational regulation in Australia are relevant in England.

In France, the enforcement processes are divided between universities and labour inspectors. This reduces the reliance on universities as regulatory actors, and potentially increases the opportunity for exploitative WIL to be identified and remedied. However, concerns about abuses continue to be expressed despite these dual enforcement avenues. ${ }^{58}$ This suggests that increasing the number of regulatory actors responsible for enforcement may be insufficient to remedy the issues identified in the Australian context.

\subsection{CONCLUSION}

In both Australia and England educational regulation articulates (generic) general principles regarding quality WIL and establishes an external regulator tasked with conducting irregular reviews to determine whether universities are compliant. It is inevitable this means internal university processes for establishing and running WIL activities significantly affect students' experiences.

This chapter has begun to explore the assumption that universities are managing WIL effectively. The data from Australia suggest that this hypothesis is incorrect. Instead, it seems Australian universities are failing to ensure:

1. employees are adequately informed about the regulatory framework governing tertiary education, including that specifically directed towards WIL;

2. processes and policies (for example, for course design and approval) are designed to ensure regulatory compliance; and

3. WIL is consistently compliant with educational regulation.

This calls into question the efficacy of a regime which relies on universities operationalizing regulation to ensure students engaged with WIL have quality learning experiences and are not exploited. While some institutions are

\footnotetext{
58 Broughton and others (n 50).
} 
focusing on developing and delivering quality WIL, the failure to consistently engage with educational regulation undermines the proposition that this is consistently the case. Lack of engagement with educational regulation is even evident in national guidance regarding WIL from one of the organizations that promotes it, the Australian Collaborative Education Network (ACEN). In June 2020 ACEN released a Quality Framework, which makes only oblique reference to the regulatory framework, suggesting that a quality indicator is that an institution maintains a 'Policy Register of relevant government and university regulations' regarding WIL. ${ }^{59}$

While there are no data available from England, the similarity of its regulation and enforcement regime mean it is probable that equivalent issues will arise. An intuitive response to the regulatory problem which has been identified in the Australian context might be to add an additional regulatory enforcer, external to the tertiary education sector, as has occurred in France. There is some suggestion, however, that the French approach of dual educational and workplace regulation and enforcement is not proving to be effective. The extent to which this is so remains to be explored, but it does cast doubt on the efficacy of adding layers of enforcement. A more productive approach may be to focus on robust and effective enforcement processes rather than multiply the number of potential enforcers. In both England and Australia, a more active enforcement role by the formal regulator (OfS and TEQSA) might be more effective in encouraging universities to develop and consistently implement more robust compliance processes.

Whether the issue is that these regulatory regimes are misconceived, poorly drafted or badly operationalized, or a combination of all three, has not yet been determined. Whatever the genesis of the problem, stakeholders that support WIL within tertiary education should be concerned about the regulatory compliance issues identified in Australia, and the potential for similar risks in England and France. As one of the interviewees in the Australian research stated:

I think we need to watch that very carefully because it is a delicate balance. If we lose focus on the need of the student and the educational requirements of the programs then we run the risk of the students being exploited and if that becomes the perception, even if it's not the reality, then that will destroy some very good education programs that do involve legitimate internships.

59 Matthew Campbell, Leoni Russell, Lindy McAllister, Lorraine Smith, Ricky Tunny, Kate Thomson, and others, Framework to Support Assurance of Institution-Wide Quality in Work Integrated Learning (ACEN 2020) 18. 